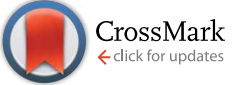

Cite this: Anal. Methods, 2016, 8, 6404

\title{
Development of an HPLC-MS method for the determination of natural pteridines in tomato samples
}

\author{
Elísabet Martín-Tornero, ${ }^{* a}$ David González Gómez, ${ }^{b}$ Isabel Durán-Merás ${ }^{a}$ \\ and Anunciación Espinosa-Mansilla ${ }^{a}$
}

In plants, reduced pteridines are folate biosynthesis intermediates, and the presence of these analytes in biofortification processes is considered crucial. A simple liquid chromatography-mass spectrometry (LCESI-MS) method has been optimized for the determination of natural pteridines in tomato samples. A solid phase extraction (SPE) step using ISOLUTE ENV cartridges has been employed for cleaning up the samples. Eleven pteridines have been assayed but only four of them have been detected and quantified in tomatoes. The stability of the pteridines and hydropteridines in tomato extracts has been studied. Validation parameters have been evaluated and good linearity $\left(R^{2}>0.99\right.$ in all cases) and precision (interday relative standard deviation values were lower than $10 \%$ ) were obtained. The amounts (as $\mu \mathrm{g}$ per $\mathrm{g}$ of fresh sample) found of each pteridine were $0.019,0.44,0.043$ and 0.087 for neopterin, 7,8dihydroneopterin, 6-hydroxymethylpterin and pterin-6-carboxylic acid, respectively.

Received 27th May 2016

Accepted 1st August 2016

DOI: 10.1039/c6ay01519k

www.rsc.org/methods

described. One of these options is the over-expression of the enzymes that are limiting steps in tetrahydrofolate biosynthesis. ${ }^{9}$ Other procedures to induce genetic modifications in plants, based on increasing the pteridine synthesis, which are intermediates in biosynthesis of folate, have been recently reported. ${ }^{\mathbf{8 1 7 - 1 9}}$ Pteridines are bicyclic compounds made up of a pyrimidine and a pyrazine ring, that occur in a wide range of living systems, including plants, where significant quantities of these analytes have been found. Chemically, folate molecules are composed of a pterin, a $p$-aminobenzoic acid (PABA) and a glutamate chain. In plants, pteridines are synthesized in the cytosol, PABA in the chloroplast and folates in the plant mitochondria, according to the pathways of Fig. 1. through the diet, and plant foodstuffs are the main source of folates. ${ }^{\mathbf{9} 10}$ However, in some cases, the amount of folates in vegetables is not enough to achieve the minimum daily requirements, ${ }^{\mathbf{1 1}}$ and different mechanisms have been proposed to increase the folate intake such as: adding synthetic folic acid to basic food (fortification); taking folic acid tablets (supplementation); or through a promising alternative, increasing the content of folates in plants by genetic engineering or biofortification. ${ }^{12-16}$

Several potential strategies to enhance folate synthesis and its accumulation in plants through biofortification have been

${ }^{a}$ Department of Analytical Chemistry and Research Institute on Water, Climate Change and Sustainability (IACYS), University of Extremadura, Badajoz, 06006, Spain. E-mail: elisabetmt@unex.es; iduran@unex.es; nuncy@unex.es; Tel: +34924289376

${ }^{b}$ Department of Didactic of Experimental Sciences, University of Extremadura, 10003, Cáceres, Spain.E-mail: dggomez@unex.es

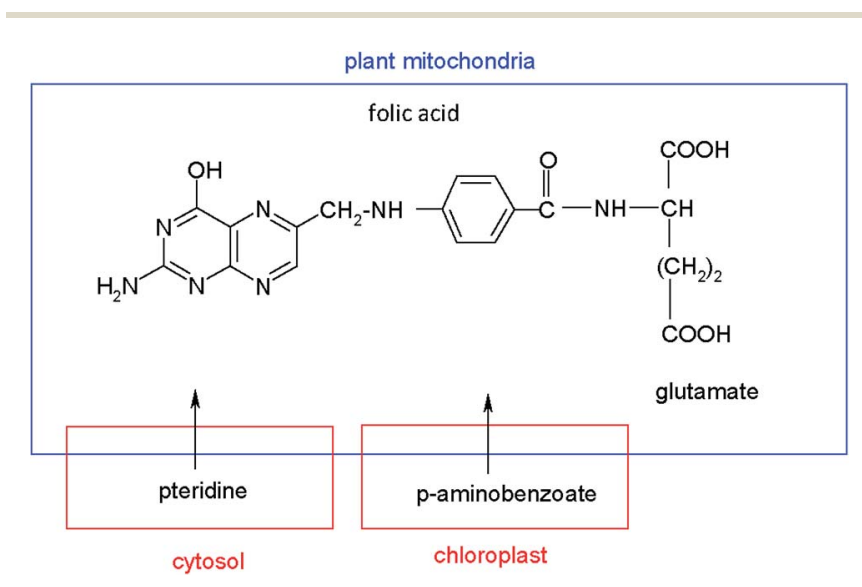

Fig. 1 Schematic pathway of folate biosynthesis in plants. 
A relevant research study ${ }^{20}$ shows the possibility of increasing the amount of pteridines in tomatoes by genetic engineering. In the mentioned paper, authors indicate that pteridine synthesis capacity drops in ripe tomato fruit, and this decline can be modified by the specific overexpression of GTP cyclohydrolase I, the first enzyme of pteridine synthesis. Although the levels of folate were significantly increased by the above modifications, the levels of PABA and pteridines are still high, which implies that other substances that inhibit the synthesis of folate exist in transgenic vegetables. Therefore, considering the future implementation of folate biofortification in plant-based foods, we should take into account the accumulation of these intermediates, and therefore it is relevant to establish methods for their analysis. ${ }^{11}$

Research studies about the content of pteridines in vegetable samples are very scarce. The lack of data of pteridine levels in plants contrasts with the abundant information about the presence of these compounds in animals and bacteria. The occurrence and quantification of unconjugated pteridines in food resources, such as beans, bananas and spinach, has been reported, and characteristic pteridine patterns were observed in each product. ${ }^{21}$ Another study has shown that plants contain small amounts of 7,8-dihydroneopterin ( $\mathrm{NH} 2)$ and 6-hydroxymethyl-7,8-dihydropterin (6HMDHPT) (detected as their oxidized forms), neopterin (NEO) and 6-hydroxymethylpterin (6HMPT). ${ }^{22}$ Crude leaves extracted from transgenic crop lines were analyzed by HPLC, and the total pteridinic compounds were expressed as NEO. ${ }^{14}$ These authors indicate that the levels of pteridines in crude extracts of non-transgenic plants are very low, but the concentration increases up to 1100 -fold in transgenic plants.

It has been described that the pteridines, NEO, monapterin (MON) and 6HMPT, as well as their potentially reduced forms and unknown pteridine glycosides, are accumulated in tomatoes. ${ }^{8}$ Díaz de la Garza et al. ${ }^{20}$ proposed a fluorimetric HPLC method for the analysis of pteridines and PABA in biofortified tomatoes. This method is based on taking representative segments of tomatoes and performing a pretreatment of the samples, using liquid-liquid extraction followed by acid $\mathrm{I}_{2} / \mathrm{I}^{-}$ pre-oxidation, in order to transform the reduced forms into the fluorescent oxidized pteridines. A scatter plot of the total pteridine level versus folate content shows that the maximal folate concentration in plants was found at pteridine levels of about 25 $\mathrm{nmol} \mathrm{g}{ }^{-1}$ of fresh weight. Higher pteridine concentrations do not increase folate levels. A total pteridine content up to about $60 \mathrm{nmol} \mathrm{g}^{-1}$ was reported in transgenic tomatoes. Later, and using the mentioned pre-oxidation step, pteridines were analyzed in biofortified tomatoes, and the total pteridine amount was expressed as 6HMPT, but the amounts of each individual pteridine were not reported. ${ }^{19}$ Also, in this paper the authors indicated that the pericarp of velvet bean (a medicinal legume) contains $470 \mathrm{nmol} \mathrm{g}^{-1}$ fresh weight of total pteridine, which is 25 times higher than the pteridine content of transgenic tomatoes. Rodrigues et al. analyzed NEO, MON, 6HMPT and pterin-6-carboxylic acid (PT6C) in spinach, beets and tomatoes. The pteridine content in wild tomato cultivars, raw spinach and raw red beets was on the order of $1 \mathrm{nmol} \mathrm{g}^{-1} .^{23}$
In all the above-proposed methods, fluorimetric detection has been used, and therefore, a pre-oxidation step of the sample to generate the fluorescent forms from non-fluorescent hydropteridines was necessary. MS detection allows the analysis of the pteridines in their oxidation state and the pre-oxidation step is avoided. This methodology has been explored in biological samples, such as urine or serum. ${ }^{24}$

HPLC hyphenated with mass spectrometry is the most widely applied methodology in the analysis of folates, because it allows qualitative and quantitative information of folate derivatives in a variety of foods and, recently, in tomatoes. ${ }^{25}$ However, the determination of pteridinic precursors in vegetables using LCMS methods has been sparingly carried out. LC-MS/MS has been applied to determine pteridines in potatoes and in Arabidopsis thaliana ${ }^{26}$ Recently, a relevant paper about the degradation of pteridines in plants during sample preparation using UHPLC-MS/MS has been published..$^{27}$ In the above mentioned paper the authors report that dihydropterins are subjected to interconversion, on column, in source and auto oxidation, and they are degraded into non-pterin products during boiling. Later, Burton et $a .^{28}$ established the pterinomic workflow for 15 pteridin derivatives in urine using HPLC-MS/MS revealing that previous oxidative steps were inefficient. The elimination of the preoxidation step in the analysis of pteridinic derivatives was previously recommended by Cañada et al.$^{29}$ It is remarkable that Burton et al. showed that 7,8-dihydroxanpthopterin exhibited negligible in-source oxidation to xanthopterin. However data about the potential oxidation of dihydroneopterin ( $\mathrm{NH} 2)$ are not reported in this paper.

Therefore, the aim of this work was to develop a simple liquid chromatography-mass spectrometry (LC-MS) method, potentially useful for the determination of natural pteridines present in different types of samples and, particularly, detecting and determining those that exist in tomato samples. A nonoxidation step is applied and we are able to determine each pteridinic compound in its natural oxidation state. Due to the controversy about the hydropteridine stability using MS detection, a study about the stability of the pteridinic reduced forms in tomato samples has also been developed in this study. Research has been focused on those pteridinic derivatives present in tomatoes such as dihydroneopterin and a soft SPE treatment has been carried out to prevent the natural oxidation state of pteridinic compounds.

\section{Experimental}

\subsection{Chemical reagents and solutions}

NH2, NEO, 6HMPT, MON, PT6C, 6HMDHPT, biopterin (BIO), pterin (PT), isoxanthopterin (ISO), xanthopterin (XAN), and 7,8dihydrobiopterin (BH2) were obtained from Schircks Laboratory (Jona, Switzerland). Dithiothreitol (DTT) and formic acid were from Sigma (Sigma-Aldrich S.A., Madrid, Spain). HPLCgrade acetonitrile (ACN) was purchased from Merck (Madrid, Spain). Methanol and hydrochloric acid were from Scharlau (Scharlau, Barcelona). Ultrapure water was obtained from a Milli-Q system (Waters Millipore, Milford, MA, USA). 
Stock standard solutions of pteridines (15-30 $\left.\mu \mathrm{g} \mathrm{mL}^{-1}\right)$ were prepared by exact weighing of each solid pteridine, dissolution in ultrapure water by adding of $0.010 \mathrm{M}$ sodium hydroxide up to $\mathrm{pH}$ near 10.5, and neutralization with $0.010 \mathrm{M}$ hydrochloric acid. $\mathrm{BH} 2$ and $\mathrm{NH} 2$ standard solutions were prepared daily in the same way as standard solutions of pteridines, but containing $0.1 \%$ DTT to minimize the spontaneous oxidation due to environmental oxygen. ${ }^{29}$ Exposure to direct sunlight was avoided. Pteridine standard solutions were stored at $-18{ }^{\circ} \mathrm{C}$ and they were stable for at least 3 weeks.

A standard working mixture solution containing $1.5 \mu \mathrm{g} \mathrm{mL}$ of each pteridine and hydropteridine was prepared by dilution of the stock standard solutions with ultrapure water. Other solutions were prepared via serial dilutions and they were used in the generation of the calibration curves.

\subsection{Instrumentation}

The chromatographic studies were performed on an Agilent 1100 LC High Performance Liquid Chromatograph (Agilent Technologies, Palo Alto, CA, USA), equipped with an online degasser, quaternary pump, autosampler Agilent 1290 infinity thermostated at $5{ }^{\circ} \mathrm{C}$, and an oven column compartment. The ChemStation software (Agilent ChemStation for LC-MS system, Rev.B.04.01) was used for controlling the instrument, data acquisition and data analysis. Chromatographic separation was achieved on an analytical column Zorbax Eclipse XDB-C18, 250$4.6 \mathrm{~mm}$ and $5 \mu \mathrm{m}$ particle size (Agilent Technologies). The column temperature was set at $22{ }^{\circ} \mathrm{C}$. Gradient mode was applied. The flow rate was set at $0.6 \mathrm{~mL} \mathrm{~min}^{-1}$ and the injection volume was $20 \mu \mathrm{L}$.

Detection was performed with an Agilent Technologies single quadrupole mass spectrometer, model 6120, equipped with an electro-spray interface (ESI) operated in the positive ionization mode. Nitrogen was used as the nebulizer gas. Mass spectrometer values of capillary voltage, nebulizer pressure, nitrogen flow rate and temperature were adjusted to $4000 \mathrm{~V}, 40$ psi, $10 \mathrm{~mL} \min ^{-1}$ and $300{ }^{\circ} \mathrm{C}$, respectively. A fragmentor voltage of $100 \mathrm{~V}$ was selected, since it provided the best sensitivity with reference compounds. Single ion monitoring (SIM) was selected as operation mode using the target ion $[\mathrm{M}+\mathrm{H}]^{+}$for all the studied compounds.

Calibration curves and analytical figures of merit were performed by means of the ACOC program, developed by our research group, in MatLab code. ${ }^{30}$

\subsection{Extraction of tomato samples}

Red ripe stage tomatoes were bought in local supermarkets. On the day of purchase and after washing, tomatoes were finely triturated and frozen in liquid nitrogen prior to lyophilization. The lyophilized tomatoes were stored at $-18{ }^{\circ} \mathrm{C}$ until needed. About one gram of lyophilized tomatoes was exactly weighed, and pteridines were extracted two times, with $10 \mathrm{~mL}$ each time, of the methanolic/water pH 12 (1/1, v/v) mixture alkalized with sodium hydroxide. In each extraction, the sample was sonicated for 15 minutes, and centrifuged at 3000 r.p.m. (10 minutes). The supernatants were recombined, neutralized, filtered, and diluted to $25 \mathrm{~mL}$ with ultrapure water. The tomato extract was stable for at least 10 days.

\subsection{Purification of tomato extracts}

Purification of samples was carried out by solid phase extraction (SPE). Aliquots of $3.0 \mathrm{~mL}$ of the tomato extracts were passed through an ISOLUTEENV+ (hydroxylated polystyrene-divinylbenzene copolymer) cartridge, previously conditioned with 5 $\mathrm{mL}$ of methanol and $5 \mathrm{~mL}$ of ultrapure water. The elution of the retained pteridines was carried out with $3.0 \mathrm{~mL}$ of acetonitrile : water, $80: 20(\mathrm{v} / \mathrm{v})$. Finally, $1.0 \mathrm{~mL}$ of the eluate was evaporated to dryness by a nitrogen stream, and the residue was re-dissolved with $1.0 \mathrm{~mL}$ of ultrapure water and filtered through a $0.2 \mu \mathrm{m}$ PTFE filter for LC-MS analysis.

\subsection{Quantification of pteridines present in tomato samples}

The standard addition method was used to calculate the concentrations of each pteridine in tomato samples. Spiked lyophilized tomato samples, at five different concentration levels for each pteridine in the range between 30 and $200 \mathrm{ng}$ $\mathrm{mL}^{-1}$, were prepared. Each sample was prepared by adding 800 $\mu \mathrm{L}$ of the tomato extract (or $200 \mu \mathrm{L}$ in the case of the determination of $\mathrm{NH} 2$ ), into a vial containing variable volumes of pteridine and hydropteridine standard working mixtures, and diluting to $1 \mathrm{~mL}$ with ultrapure water. Peak areas of the Extracted Ion Chromatogram (EIC) were used for the quantification of all the assayed species.

\subsection{Sensitivity, precision and accuracy}

Limits of detection (LODs) were calculated according to the Long and Winefordner criterion ${ }^{31}(k=3)$, and limits of quantification (LOQs) as $(\mathrm{LOD} / 3) \times 10$, using spiked tomato samples at five concentration levels (by triplicate). The accuracy of the proposed method was calculated for tomato samples spiked at five concentration levels between 30 and $200 \mathrm{ng} \mathrm{mL}^{-1}$ in triplicate. Intraday $(n=6)$ and interday $(n=5)$ precision assays were carried out in samples containing NH2, NEO, 6HMPT and PT6C at the LOQ amount, and expressed as the relative standard deviation (RSD).

\section{Results and discussion}

\subsection{Optimization of MS variables}

The optimization of MS parameters and LC separation conditions was based on previous experiments developed by our research group for the determination of pteridines in biological fluids. $^{24}$

Flow injection analysis (FIA) of each pteridine standard solution was performed with the aim to optimize fragmentor voltage (FV), capillary voltage (CV), nebulizer pressure (NP), nitrogen flow rate and temperature, in ESI positive and negative modes, in order to obtain the highest sensitivity. Three FV values of 50, 75 and $100 \mathrm{~V}$, in negative mode, and two FV values of 75 and $100 \mathrm{~V}$, in positive mode, were assayed. Two CV values of 4000 and $4500 \mathrm{~V}$ were tested in both modes. The best results were obtained with 100 and $4500 \mathrm{~V}$ for FV and CV respectively in 
negative mode, and with $100 \mathrm{~V}$ for FV and 4000 or $4500 \mathrm{~V}$ for $\mathrm{CV}$, in positive mode. The results show that the protonated molecular ion $[\mathrm{M}+\mathrm{H}]^{+}$can be selected as the target ion of the analytes due to the presence of easily protonated amino groups in the molecules. Also, the electrospray in positive mode is more stable than in negative mode. The instrumental variables were optimized to obtain the highest sensitivity of the $[\mathrm{M}+\mathrm{H}]^{+}$ion, using the SIM mode with FV and CV at 100 and $4500 \mathrm{~V}$, respectively.

NP was varied between 10 and 55 psi and the abundance remains constant for psi values higher than 30 . The best signal/ noise ratio was obtained for a gain value of 15 . The nitrogen flow rate and temperature do not significantly affect the abundance and $10 \mathrm{~mL} \min ^{-1}$ and $300{ }^{\circ} \mathrm{C}$ were selected for later studies.

\subsection{Optimization of the LC separation}

Once MS parameters were established, chromatographic conditions were optimized in order to attain an adequate elution of the target compounds and a short analysis time. The mobile phase composition was evaluated considering the different polarities of the pteridines analyzed, and the identical molecular-ions for NEO and MON, and for XAN and ISO. The presence of very low amounts of organic solvents such as methanol or ACN, in the mobile phase, generates a drastic diminishing of the capacity factor of the more polar compounds. However, a notable amount of organic solvent is necessary to elute the less polar compounds. On the other hand, a slightly acidic medium is necessary to avoid the formation of charged pteridines that are poorly retained. These facts indicate the necessity of applying a gradient mode for the elution of the pteridinic compounds and, in this sense, various analytical gradients were evaluated with different formic acid solutions, and ACN or methanol as organic phases. The better resolution and the higher ion abundance were obtained with mixtures of $0.1 \%$ formic acid containing $2 \%$ of ACN (solution A), and pure ACN containing $2 \%$ of formic acid (solution B). The optimized gradient was: $100 \%$ of eluent A during the first 8 min, increasing the percentage of eluent B up to $20 \%$ (in $8 \mathrm{~min}$, $2.5 \% \mathrm{~min}^{-1}$ ). These conditions were maintained for $4 \mathrm{~min}$ and, finally, the eluent B content was decreased to the initial conditions ( $0 \% \mathrm{~B})$, and the column was re-equilibrated for $10 \mathrm{~min}$. The flow rate was set constant at $0.6 \mathrm{~mL} \mathrm{~min}^{-1}$, the injection volume was $20 \mu \mathrm{L}$, and the column temperature was kept at $22^{\circ} \mathrm{C}$. Fig. 2 shows the EICs obtained from a stock standard mixture of the 11 pteridines under these optimized conditions. Moreover in Table 1 , the retention times for each pteridine and the $\mathrm{m} / \mathrm{z}$ relation for the $[\mathrm{M}+\mathrm{H}]^{+}$ions, in a standard solution containing the eleven pteridinic and hydropteridinic derivatives, are summarized. In the mentioned table, resolution values in the EIC chromatogram obtained for those compounds with identical molecular-ions, such as NEO-MON and XAN-ISO, are shown.

\subsection{SPE cleanup process in tomato samples}

When MS detection is used in the analysis of complex matrix samples, such as vegetables, a cleanup step prior to chromatographic separation is usually recommended. The cleanup step is intended to protect the chromatographic column, and minimize the matrix effect. SPE is the selected methodology in most of the food bibliographic data due to its easy use, speed and variety of adsorbents. In our case, tomato samples were cleaned by SPE, using the ISOLUTEENV (200 mg) cartridge with the hydroxylated polystyrene-divinylbenzene copolymer as the sorbent. In the first place, the cartridge was conditioned with 5 $\mathrm{mL}$ of $100 \%$ methanol and then flushed with $5 \mathrm{~mL}$ of ultrapure water. The extraction procedure was assayed with $3.0 \mathrm{~mL}$ of the extracts of tomatoes spiked with pteridines between 150 and $300 \mu \mathrm{g} \mathrm{mL} \mathrm{m}^{-1}$. With the object of verifying if the pteridines were retained in the cartridge, the eluate was injected into the chromatographic system. The absence of any signal at the same retention time of the selected compounds indicates that pteridines have been retained. The elution of pteridines was tested with different solvents, such as ACN, methanol, and different mixtures of the organic solvents in ultrapure water, 80/20, 50/50 and 20/80 (v/v, organic solvent : ultrapure water), in order to achieve the maximum recovery. A pneumatic manifold allowed us to elute simultaneously twenty four tomato samples using a precise and repetitive flow of eluent. The best recovery values were obtained using between 1.5 and $3 \mathrm{~mL}$ of acetonitrile-water $80: 20, \mathrm{v} / \mathrm{v}$. The repeatability of the SPE extraction procedure was checked with nine independent extracts, and the average recovery values ranged between $80 \%$ for XAN and ISO and $118 \%$ for $\mathrm{BH} 2$. Similar recovery values were obtained when the elution was performed with $1.5 \mathrm{~mL}$ or $3 \mathrm{~mL}$ of the elution mixture.

\subsection{Application to the analysis of pteridines in tomato samples}

In the first place and with the object of focusing the research on compounds that are present in tomatoes, an unspiked aliquot of the tomato extract and a spiked sample with a standard mixture of pteridines was injected into the chromatographic system. The extracted-ion chromatograms (EICs) obtained in SIM mode are shown in Fig. 3. Only four pteridines were detected in the tomato samples: NEO, NH2, 6HMPT and PT6C but, due to bibliographic data that indicate the presence of MON in tomatoes, ${ }^{19}$ this pteridine was also investigated in later studies. From this point, the studies were centered in these five pteridines and hydropteridines.

\subsection{Stability of the pteridines in the tomato extract}

Due to the known instability of the aqueous solutions of hydropteridines, aliquots of the same tomato extract, spiked with NEO, NH2, 6HMPT and PT6C, were analyzed for 20 days, to establish the stability of the extracted tomato solution. The average value of the relative abundance of three injections for the selected pteridines during 20 days is represented in Fig. 4a, which shows that for NEO, 6HMPT and PT6C, it remains constant for the first ten days, and decreases after that. NH2 is the pteridine presenting minor stability, remaining unchanged only for 7 days, and their relative abundance decreases a third of its initial value after 20 days. A week was fixed as the maximum time for analysis after preparation of the tomato sample. 

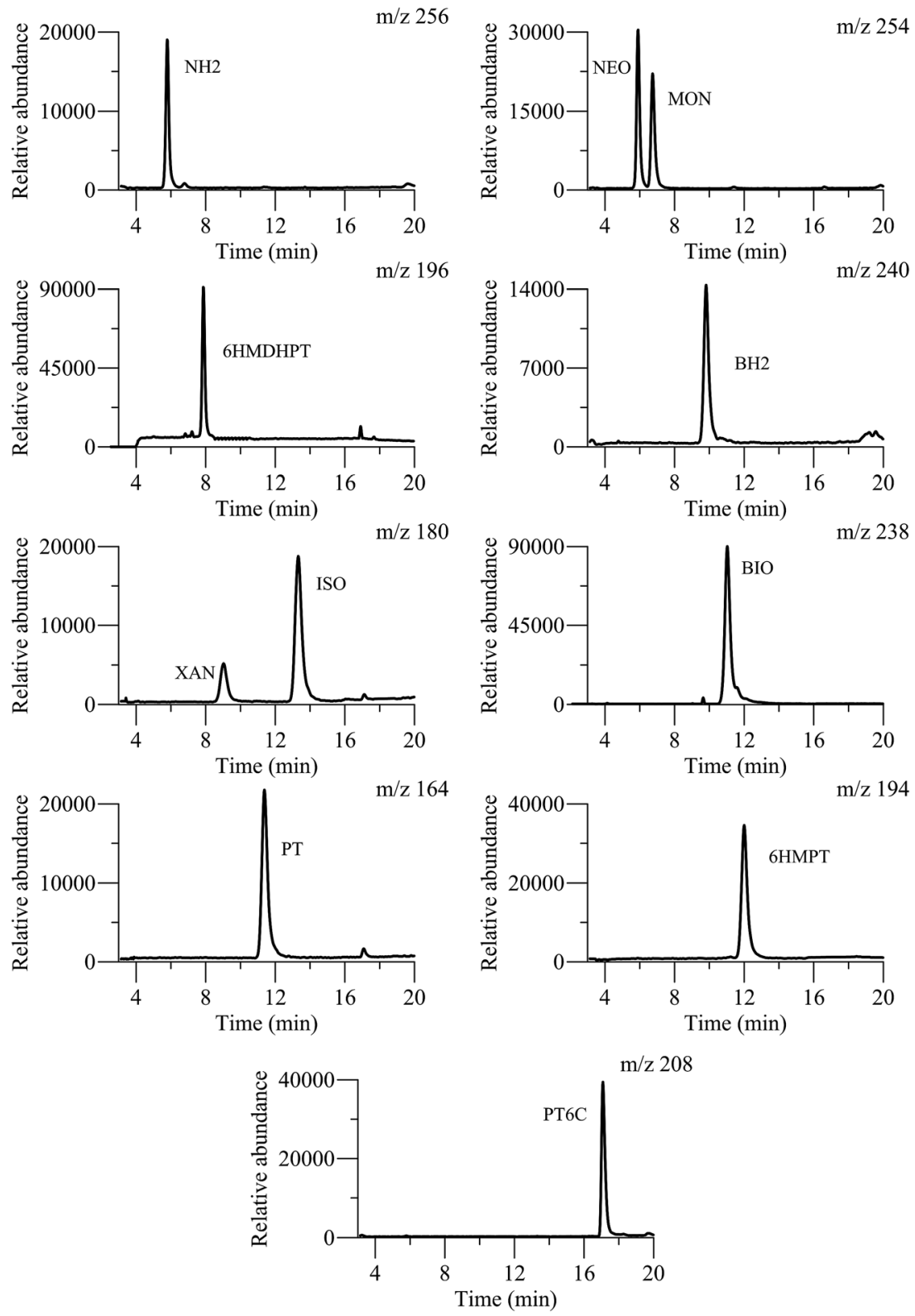

Fig. 2 ElCs obtained from the analysis of a standard pteridine mixture with the optimized separation method.

Furthermore, and in order to test if the target compounds undergo degradation and/or interconversion processes, tomato extracts were individually spiked with each pteridine and subjected to the SPE clean-up step. For each solution, the signals in the MS detector were simultaneously monitored for the $\mathrm{m} / \mathrm{z}$ of all ions. This study has also been done with standard solutions. We have seen no evidence of degradation of the pteridines when they are treated with this procedure. As hydropterines are more unstable and easily oxidizable, an exhaustive study was carried out with NH2. In the first place, and with a standard solution of $\mathrm{NH} 2$, subjected to the SPE clean step, EICs at $\mathrm{m} / \mathrm{z}$ values of 256 and 254, corresponding to $\mathrm{NH} 2$ and NEO (oxidized pteridine) respectively, were obtained. Fig. $4 \mathrm{~b}$ shows both chromatograms, where it can be appreciated a very small signal corresponding to $\mathrm{NEO}$, practically negligible compared with the signal from $\mathrm{NH} 2$ indicating that the oxidation is minimal. In the second place, we have studied the tomato sample. For this, we have compared the extracted ion chromatograms, for $\mathrm{m} / \mathrm{z}$ values of 256 and 254, obtained from spiked tomato samples at two different levels, $100 \mathrm{ng} \mathrm{mL}^{-1}$ and $200 \mathrm{ng} \mathrm{mL} \mathrm{m}^{-1}$ of $\mathrm{NH} 2$. In Fig. 4c, it can be observed that the $\mathrm{NH} 2$ signal (at $m / z 256$ ) increases when the amount of $\mathrm{NH} 2$ increases, as expected. However, the signal corresponding to NEO $(\mathrm{m} / \mathrm{z} 254)$ remains constant. This allows us to confirm that in this matrix, and with the sample treatment proposed, in the presence of organic solvent and at room temperature, $\mathrm{NH} 2$ is stable. These data are contradictory with the results reported by Van Daele and co-workers. ${ }^{27}$ However, results similar to ours have been recently described by Burton et al. ${ }^{28}$ who found negligible in-source oxidation of 7,8-dihydroxanthopterin to xanthopterin. 
Table 1 Separation characteristics of pteridines in LC-ESI-MS using gradient elution mode ${ }^{a}$

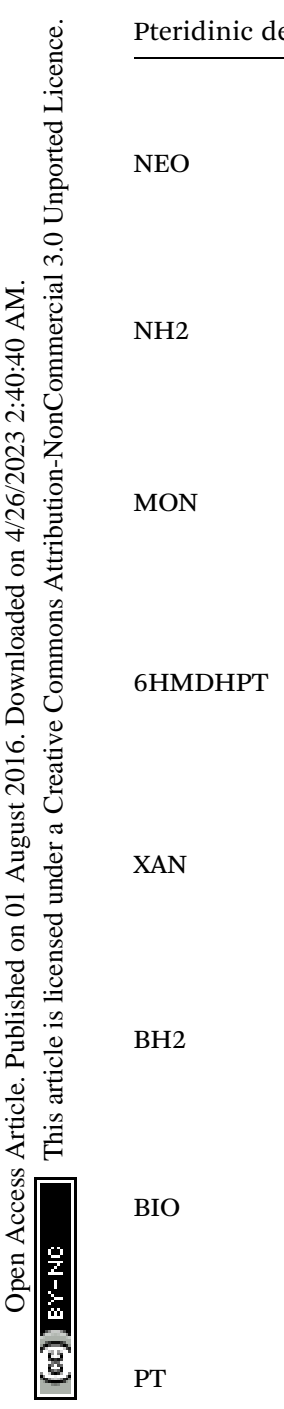

6HMPT

ISO

PT6C<smiles>Nc1nc2ncc(C(=O)O)nc2c(=O)[nH]1</smiles><smiles>Nc1cc2ncc(C(O)C(O)CO)nc2c(=O)[nH]1</smiles><smiles>CC(C)(C)C1COc2cc(N)[nH]c(=O)c21</smiles>

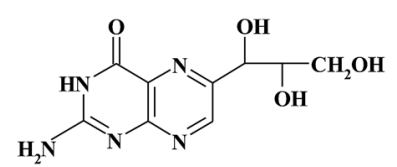<smiles>Nc1nc2c(c(=O)[nH]1)N=C(CO)CN2</smiles><smiles>Nc1nc2ncc(=O)[nH]c2c(=O)[nH]1</smiles>

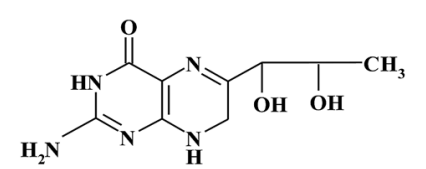<smiles></smiles><smiles>Nc1nc2nccnc2c(=O)[nH]1</smiles><smiles>Nc1nc2ncc(CO)nc2c(=O)[nH]1</smiles>

194

$$
R_{\mathrm{ISO} / \mathrm{XAN}}=10.48
$$

$R_{\mathrm{MON} / \mathrm{NEO}}=2.98$

\footnotetext{
${ }^{a}$ Fragmentor voltage: $100 \mathrm{~V}$, capillary voltage: $4500 \mathrm{~V}$, nebulizer pressure: $30 \mathrm{psi}$, temperature: $300{ }^{\circ} \mathrm{C}$.
} 
TOMATO
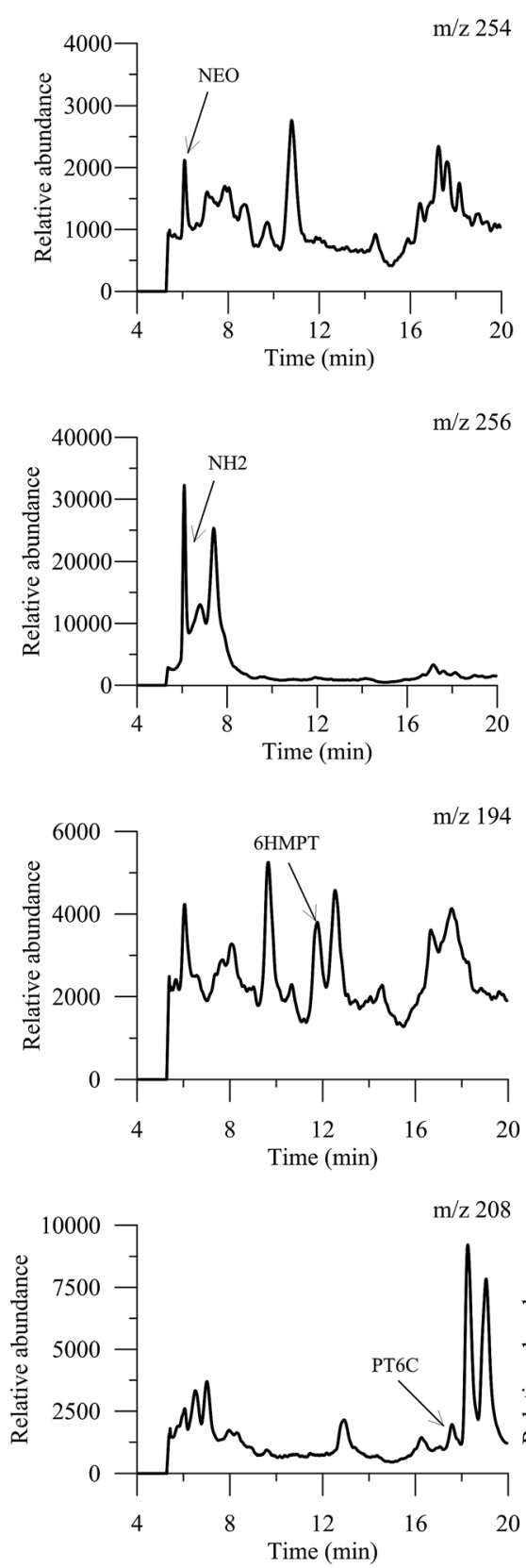

SPIKED TOMATO
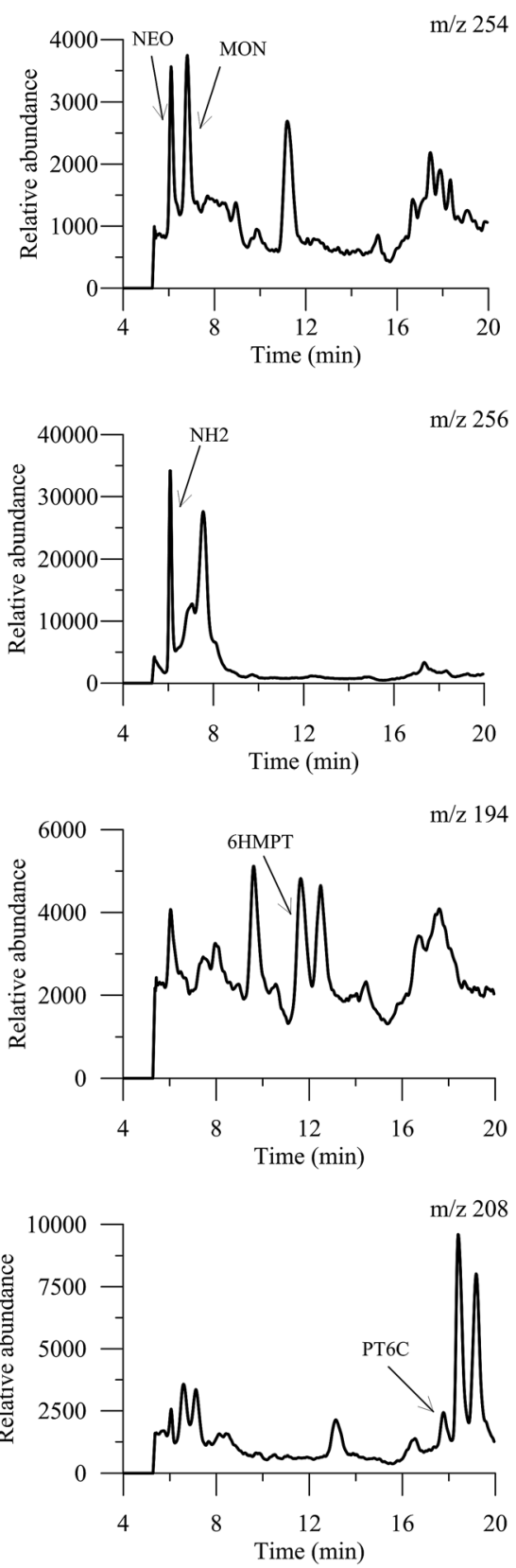

Fig. 3 EICs of an unspiked tomato sample and a spiked tomato sample.

\subsection{Study of the matrix effect}

Before performing the calibration and quantification of the pteridines, the influence of the matrix over the HPLC-ESI-MS method was evaluated. For this, a comparison of the slopes between external calibration curves in ultrapure water, and standard addition curves with tomato extracts spiked with $\mathrm{NH} 2$, NEO, MON, 6HMPT and PT6C, at five different concentrations in the range $0-200 \mathrm{ng} \mathrm{mL}^{-1}$, in triplicate, was carried out.

The matrix effect was studied with extracts of tomatoes before and after the SPE cleanup. In both cases, for each pteridine, the regression plot was obtained and the comparison between the slopes of external calibration and standard addition was accomplished applying the $F$ and $t$ statistical tests at the $95 \%$ confidence level. ${ }^{32}$ The matrix effect, expressed as percentage, was calculated as: $\%$ matrix effect $=100 \times$ (tomato/ water slope ratio) -100 .

When the non-SPE clean up extracts were analyzed, statistical differences are observed between both external standard and standard addition calibration slopes. This fact indicates a matrix effect for the analysis of all pteridines exhibiting an absolute value in the range $29.5-69.2 \%$. For most of the pteridines, a matrix suppression effect was observed, although for 6HMPT an ion enhancement effect was observed. When SPE clean up treatment was used, a softer matrix effect was observed 

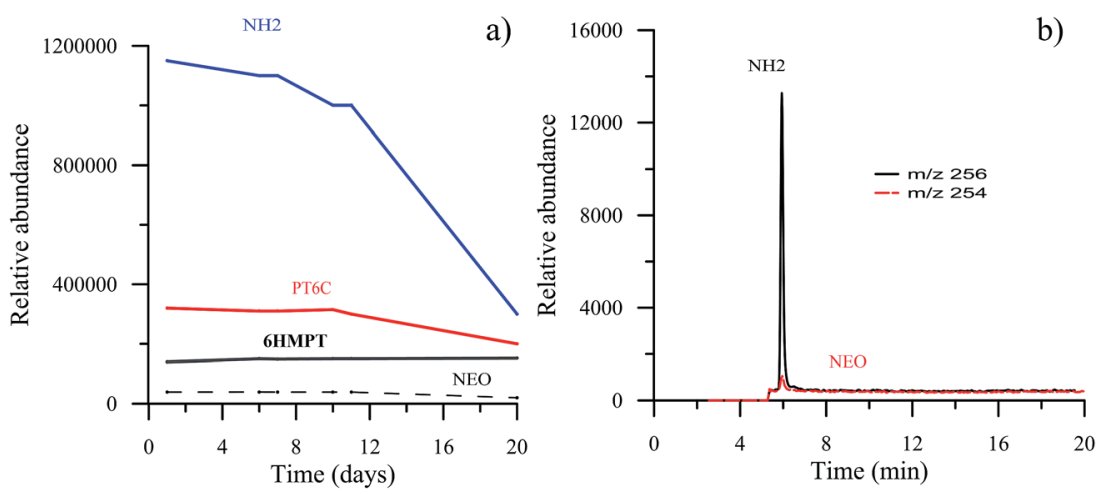

b)

$\mathbf{m} / \mathbf{z} 256$

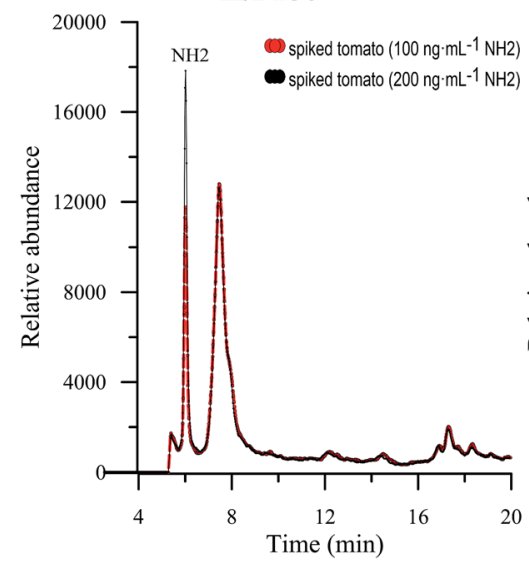

$\mathrm{m} / \mathrm{z} 254$

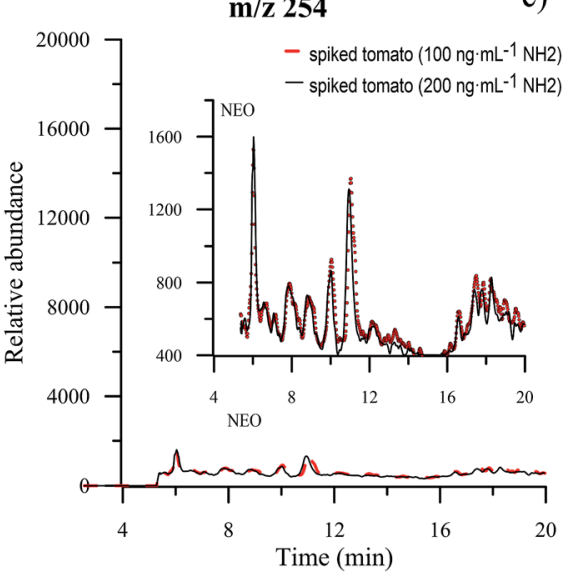

Fig. 4 (a) Stability of the pteridines detected in tomatoes. (b) Extracted ion chromatograms of a standard solution of $\mathrm{NH} 2$ at 256 and $254 \mathrm{~m} / \mathrm{z}$ values. (c) Extracted ion chromatograms of tomato extracts spiked with $\mathrm{NH} 2$ at 100 and $200 \mathrm{ng} \mathrm{mL}^{-1}$.

with absolute values between 6.3 and $50.4 \%$, particularly for $\mathrm{NH} 2$, NEO and PT6C, however for MON the results were not improved. Then, the standard addition methodology, previous SPE cleanup, was recommended for analyzing pteridines in tomato samples.

\subsection{Validation of the method}

Linearity has been established in cleaned SPE lyophilized tomato extracts, in the range $\mathrm{LOQ}-300 \mathrm{ng} \mathrm{mL}^{-1}$. Different linearity ranges were obtained depending on the compound and statistical parameters were calculated. Good linearity was observed for the five pteridines, and determination coefficients $\left(R^{2}\right)$ were higher than 0.99 for all analytes. The results of the least squares regression analysis for the standard calibrations and detection and quantification limits are summarized in Table 2. LODs ranged between 8 and $12 \mathrm{ng} \mathrm{mL}{ }^{-1}$. The lowest limit of detection was found for NEO $\left(8 \mathrm{ng} \mathrm{mL}{ }^{-1}\right)$ and very similar LOD values were obtained for MON, NH2 and PT6C. LOQs ranged from 27 to $41 \mathrm{ng}$ $\mathrm{mL}^{-1}$. To evaluate the repeatability (intraday precision, $n=6$ ) of the method, RSDs were evaluated with solutions of SPE clean tomato extracts containing $27 \mathrm{ng} \mathrm{mL}^{-1}$ of NEO, $40 \mathrm{ng} \mathrm{mL} \mathrm{mL}^{-1}$ of MON, $41 \mathrm{ng} \mathrm{mL}^{-1}$ of NH2, $35.0 \mathrm{ng} \mathrm{mL}^{-1}$ of 6HMPT, and $40.7 \mathrm{ng}$ $\mathrm{mL}^{-1}$ of PT6C. Interday precision (reproducibility) was analyzed over 5 consecutive days at the same concentration levels. Intraday precision ranged from $1.1 \%$ for NEO and 6HMPT up to $4.1 \%$ for $\mathrm{NH} 2$, and interday precision values are lower than $9.6 \%$ for all analytes, which indicates the good repeatability of the proposed method.

\subsection{Analysis of tomato samples}

Finally, the proposed LC-ESI-MS method was applied to the analysis of tomato samples. The standard addition methodology was employed and the tomato extracts were spiked at five concentration levels, for each pteridine, in the range between 30 and $200 \mathrm{ng} \mathrm{mL}^{-1}$. Samples were prepared in triplicate, and the results are shown in Table 3 as mean values and recoveries. Accuracy was evaluated through the calculation of percent recoveries for each pteridine and, in all cases, satisfactory values between 83 and $117 \%$ were obtained. The amounts of pteridines obtained from lyophilized tomatoes are also shown in Table 3. For the oxidized pteridines, the concentrations found are 0.075 nmol g${ }^{-1}$ of NEO, $0.22 \mathrm{nmol} \mathrm{g}^{-1}$ of 6HMPT, and $0.42 \mathrm{nmol} \mathrm{g}^{-1}$ of PT6C. And for the hydropteridine NH2, $1.72 \mathrm{nmol} \mathrm{g}^{-1}$ was found. These results are in accordance with those previously reported by Rodrigues et al. These authors, in a previous paper, have quantified several pteridines in wild-type tomatoes using HPLC-fluorimetric detection..$^{23}$ The reported pteridine content was on the order of $1 \mathrm{nmol} \mathrm{g}^{-1}$, but in this procedure $\mathrm{NH} 2$ was 
Table 2 Statistical regression parameters for cleaned tomato samples

\begin{tabular}{|c|c|c|c|c|c|}
\hline Parameters & NEO & MON & NH2 & $6 \mathrm{HMPT}$ & PT6C \\
\hline Intercept $\pm \mathrm{Sa}^{b}$ & $6331 \pm 1856$ & $1182 \pm 535$ & $33990 \pm 223$ & $56853 \pm 9260$ & $22113 \pm 1971$ \\
\hline Linearity $^{c}(\%)$ & 98 & 97 & 98 & 97 & 98 \\
\hline $\mathrm{LOD}^{d}\left(\mathrm{ng} \mathrm{mL}^{-1}\right)$ & 8.1 & 12.0 & 12.3 & 10.5 & 12.2 \\
\hline $\mathrm{LOQ}^{e}\left(\mathrm{ng} \mathrm{mL}^{-1}\right)$ & 27.0 & 40.0 & 41.0 & 35.0 & 40.7 \\
\hline
\end{tabular}

${ }^{a}$ Sb: slope standard deviation. ${ }^{b}$ Sa: intercept standard deviation $(n=15) .{ }^{c} \alpha=\beta=0.05 .{ }^{d}$ LOD, limit of detection according to the LongWinefordner criterium $(k=3) .{ }^{e} \mathrm{LOQ}$, limit of quantification: $\mathrm{LD} \times 10 / 3$.

Table 3 Recovery values for spiked tomato samples

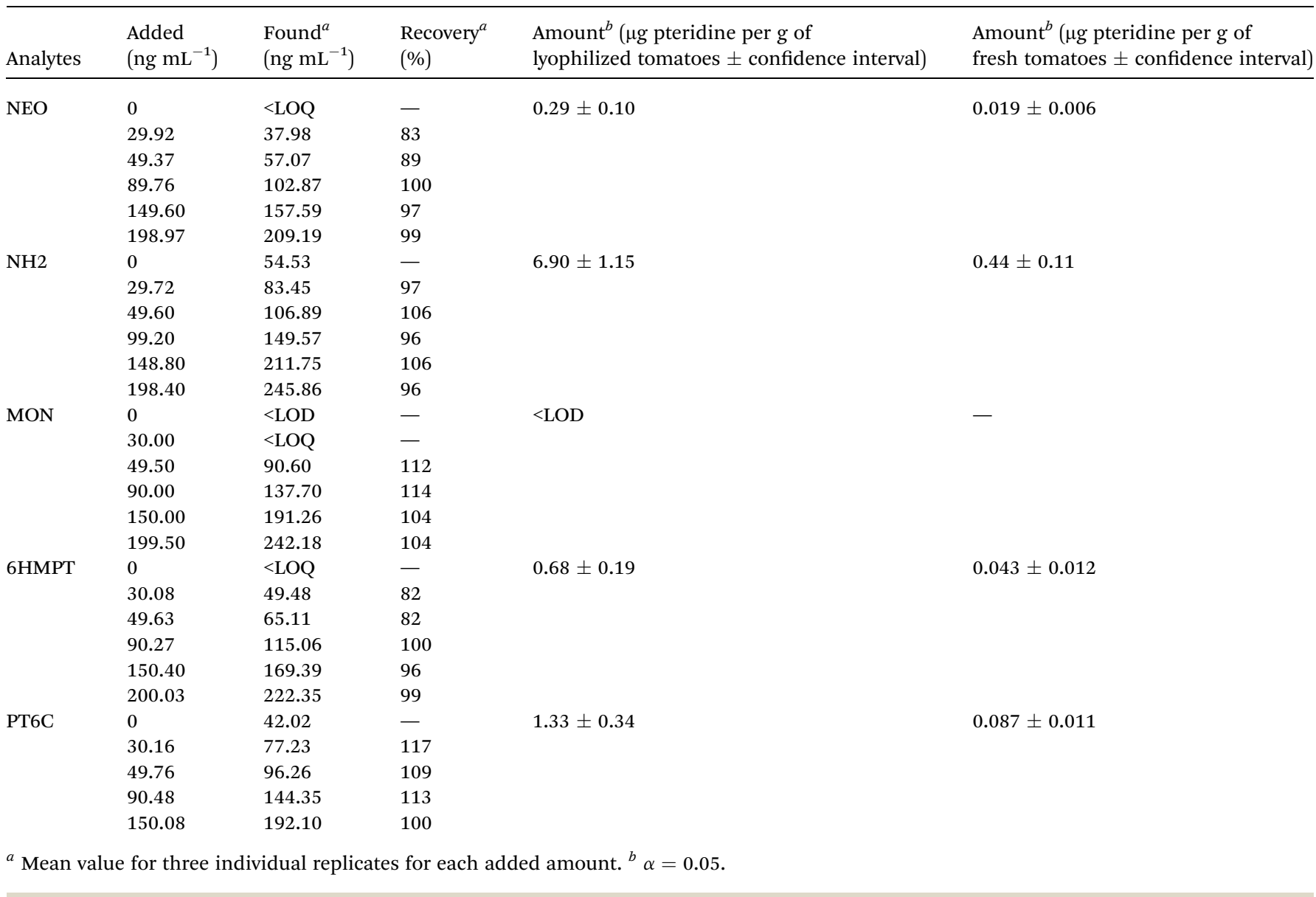

not detected due to the previous oxidation step, necessary in the HPLC-fluorimetric method.

Taking into account the lyophilized process applied, and the average water content $(93.5 \pm 2.0 \%)$ of the assayed tomato samples, the concentrations of the pteridines have also been expressed as $\mu \mathrm{g}$ pteridine per $\mathrm{g}$ of fresh tomatoes, and $0.019 \pm$ $0.006 ; 0.44 \pm 0.11 ; 0.043 \pm 0.012$ and $0.087 \pm 0.011$ for NEO, NH2, 6HMPT and PT6C, respectively were obtained. The obtained results indicate that $\mathrm{NH} 2$ is the most abundant compound and NEO is the compound in a smaller concentration. MON was not detected under the assayed conditions.

\section{Conclusions}

Therefore, a new analytical HPLC-ESI-MS method has been developed to determine precursors of folates in tomatoes as an alternative to fluorimetric detection that does not allow the determination of hydropteridine compounds or HPLC-MS/MS because not everyone has this technology available.

The proposed method allows a simple determination of the natural forms of pteridines in tomatoes by LC-ESI-MS. On the other hand, the use of a simple quadrupole analyzer eases its use as an easy and robust detector in routine analysis. With the 
object to keep the natural composition of the reduced pteridines in the tomato samples, preoxidation steps and boiling processes are avoided. Under the proposed conditions, the oxidation of the dihydroneopterin in tomatoes is negligible. This method could be useful for monitoring pteridine formation in biofortification studies to provide overproduction of folates in tomatoes, and it could be easily modified with similar aims to analyze other vegetables.

\section{Abbreviations}

$\begin{array}{ll}\text { ACN } & \text { Acetonitrile } \\ \text { BH2 } & \text { 7,8-Dihydrobiopterin } \\ \text { BIO } & \text { Biopterin } \\ \text { CV } & \text { Capillary voltage } \\ \text { DTT } & \text { Dithiothreitol } \\ \text { EICs } & \text { Extracted ion chromatograms } \\ \text { ESI } & \text { Electro-spray interface } \\ \text { FIA } & \text { Flow injection analysis } \\ \text { FV } & \text { Fragmentor voltage } \\ \text { ISO } & \text { Isoxanthopterin } \\ \text { 6HMDHP } & \text { 6-Hydroxymethyl-7,8-dihydropterin } \\ \text { 6HMPT } & \text { 6-Hydroxymethylpterin } \\ \text { LC-ESI-MS } & \text { Liquid chromatography-mass spectrometry } \\ \text { LC-MS } & \text { Liquid chromatography-mass spectrometry } \\ \text { LOD } & \text { Limits of detection } \\ \text { LOQ } & \text { Limits of quantification } \\ \text { MON } & \text { Monapterin } \\ \text { NEO } & \text { Neopterin } \\ \text { NH2 } & \text { 7,8-Dihydroneopterin } \\ \text { PABA } & \text { p-Aminobenzoic acid } \\ \text { PT } & \text { Pterin } \\ \text { PT6C } & \text { Pterin-6-carboxylic acid } \\ \text { RSD } & \text { Relative standard deviation } \\ \text { SIM } & \text { Single ion monitoring } \\ \text { SPE } & \text { Solid phase extraction step } \\ \text { TIC } & \text { Total ion chromatogram } \\ \text { XAN } & \text { Xanthopterin } \\ \end{array}$

\section{Acknowledgements}

The authors are grateful to the Ministerio de Economía y Competitividad of Spain (Project CTQ2014-52309-P) and the Junta de Extremadura (GR15090-Research Group FQM003), both co-financed by the European FEDER funds, for financially supporting this work. E. Martín-Tornero thanks Ministerio de Economía y Competitividad of Spain and European social founds for a FPI grant with reference BES-2015-075407 (Order ECC/1402/2013, de 22 of July, modified by the order ECC/1820/ 2014 , of 26 of September, and by the order ECC/2483/2014, of 23 of December; BOE no. 140 of 12/06/15).

\section{References}

1 R. J. Cook, Arch. Biochem. Biophys., 2001, 392, 226-232.
2 P. J. Stover, in Folate in Health and Disease, ed. L. B. Bailey, CRC Press, Taylor \& Francis Group, Gainesville, FL, USA, 2nd edn, 2009, pp. 49-74.

3 J. I. Rader and B. O. Schneemann, Pediatrics, 2006, 117, 1394-1399.

4 P. De Wals, F. Tairou, M. I. Van Allen, S. Uh, R. B. Lowry, B. Sibbald, J. A. Evans, M. C. Van den Hof, P. Zimmer, M. Crowley, B. Fernandez, N. S. Lee and T. Niyonsenga, N. Engl. J. Med., 2007, 357, 135-142.

5 S. Seshadri, A. Beiser, J. Selhub, P. F. Jacques, I. H. Rosenberg, R. B. P. D'Agostino, W. F. Wilson and P. A. Wolf, N. Engl. J. Med., 2002, 346, 476-483.

6 O. Stanger, Cell. Mol. Biol., 2004, 50, 953-988.

7 S. W. Choi and S. Friso, Clin. Chem. Lab. Med., 2005, 43, 1151-1157.

8 D. Blancquaert, S. Storozhenko, K. Loizeau, H. De Steur, V. De Brouwer, J. Viaene, S. Ravanel, F. Rebeille, W. Lambert and D. Van Der Straeten, Crit. Rev. Plant Sci., 2010, 29, 14-35.

9 J. Scott, F. Rébeillé and J. Fletcher, J. Sci. Food Agric., 2000, 80, 795-824.

10 E. J. Konings, H. H. Roomans, E. Dorant, R. A. Goldbohm, W. H. Saris and P. A. Van den Brandt, Am. J. Clin. Nutr., 2001, 73, 765-776.

11 D. DellaPenna, Proc. Natl. Acad. Sci. U. S. A., 2007, 104, 36753676.

12 D. DellaPenna, Science, 1999, 285, 375-379.

13 E. Bouis, J. Nutr., 2002, 132, 491-494.

14 T. Hossain, I. Rosenberg, J. Selhub, G. Kishore, R. Beachy and K. Schubert, Proc. Natl. Acad. Sci. U. S. A., 2004, 101, 5158-5163.

15 A. D. Hanson and J. F. Gregory III, Annu. Rev. Plant Biol., 2011, 62, 105-125.

16 D. Blancquaert, H. De Steur, X. Gellynck and D. Van Der Straeten, J. Exp. Bot., 2014, 65, 895-906.

17 G. J. Basset, E. P. Quinlivan, S. Ravanel, F. Rébeillé, B. P. Nichols, K. Shinozaki, M. Seki, L. C. Adams-Phillips, J. J. Giovannoni, J. F. Greegory III and A. D. Hanson, Proc. Natl. Acad. Sci. U. S. A., 2004, 101, 1496-1501.

18 G. J. Basset, R. Ravanel, E. P. Quinlivan, R. White, J. J. Giovannoni, F. Rébeillé, B. P. Nichols, K. Shinozaki, M. Seki, J. F. Gregory III and A. D. Hanson, Plant J., 2004, 40, 453-461.

19 R. I. Díaz de la Garza, J. F. Gregory III and A. D. Hanson, Proc. Natl. Acad. Sci. U. S. A., 2007, 104, 4218-4222.

20 R. Díaz de la Garza, E. P. Quinlivan, S. M. Klaus, G. J. Basset, J. F. Gregory III and A. D. Hanson, Proc. Natl. Acad. Sci. U. S. A., 2004, 101, 13720-13725.

21 M. Kohashi, K. Tomita and K. Iwai, Agric. Biol. Chem., 1980, 44, 2089-2094.

22 A. Goyer, V. Illarionova, S. Roje, M. Fischer, A. Bacher and A. D. Hanson, Plant Physiol., 2004, 135, 103-111.

23 V. Rodrigues da Silva, E. P. Quinlivan, A. D. Hanson and J. F. Gregory, FASEB J., 2007, 21, A346.

24 A. Jiménez, E. Martín-Tornero, M. C. Hurtado Sánchez, I. Durán Merás and A. Espinosa-Mansilla, Talanta, 2012, 101, 465-472. 
25 K. Tyagi, P. Upadhyaya, S. Sarma, V. Tamboli, Y. Sreelakshmi and R. Sharma, Food Chem., 2015, 179, 76-84.

26 D. Blancquaert, S. Storozhenko, J. Van Daele, C. P. Stove, R. G. Visser, W. E. Lambert and D. Van der Straeten, J. Exp. Bot., 2013, 64, 3899-3909.

27 J. Van Daele, D. Blancquaert, F. Kiekens, D. Van der Straeten, W. E. Lambert and C. P. Stove, Food Chem., 2016, 194, 11891198.

28 C. Burton, H. Shi and Y. Ma, Anal. Chim. Acta, 2016, 927, 7281.
29 F. Cañada-Cañada, A. Espinosa-Mansilla, A. Muñoz de la Peña and A. Mancha de Llanos, Anal. Chim. Acta, 2009, 648, 113-122.

30 A. Espinosa-Mansilla, A. Muñoz de la Peña and D. González Gómez, Chem. Educ., 2005, 10, 337-346.

31 G. L. Long and J. D. Winefordner, Anal. Chem., 1983, 55, 712A-724A.

32 D. L. Massart, B. G. M. Vandeginste, L. M. C. Buydens, S. De Jong, P. J. Lewi and J. Smeyers-Verbeke, in Handbook of Chemometrics and Qualimetrics: Part A, Elsevier, Amsterdam, 1997, vol. 20. 